pletely beyond 100 days after the operation. The freedom from surgical reintervention was very acceptable.

\section{Resource Consumption}

Different types of resources, both human and material, are used in treating patients undergoing $\mathrm{CABG}$ in cardiogenic shock and during CPR. The consequences of treating these patients will differ considerably between health care economic systems. In some countries these will be just additional charges, whereas in others these will be unrecoverable costs. The most visible resource consumption, hospital stay, was only doubled in these patients. This event was once more influenced by the competing early hospital mortality. A higher price was paid for the use of hemodialysis and support devices. Some survivors with stroke have been confronted with the medical and socioeconomic consequences of this condition and the partly failed therapy.

Our departmental policy has changed to mandating an immediate surgical approach consisting of initiation of extracorporeal circulation for all patients in cardiogenic shock or receiving CPR and amendable by CABG. If the first arterial $\mathrm{pH}$ is less than 6.9, we advise discontinuation of all therapy and urge the caregiver to proceed with extreme caution if the $\mathrm{pH}$ is less than 7.1. The use of additional resources (dialysis, intermediary, and long-term mechanical support) is weighed against the life expectancy (judged by the presence and severity of comorbidity).

Patients undergoing CABG in cardiogenic shock and during CPR have disrupted the surgical routine of coronary surgery. They have induced an additional opportunistic resource cost.

The appropriate use of health care resources in a population is a delicate balance between an individual patient's rights and the collective responsibility of the community. This study suggests that health care purchasers should allow and cover this approach. Clinicians should continue the search for clinical discriminative markers guided but not driven by available variables.

\section{References}

1. Nashef S, Roques F, Michel P, Gauducheau E, Lemeshow S, Salamon $\mathrm{R}$, et al. European system for cardiac operative risk evaluation (EuroSCORE). Eur J Cardiothorac Surg. 1999;16:9-13.

2. Flameng W, Daenen W, Borgers M, Thoné F, Xhonneux R, Van de Water A, et al. Cardioprotective effects of lidoflazine during 1 hour normothermic global ischaemia. Circulation. 1981;64:796-807.

3. von Segesser LK, Lehmann K, Turina M. Deleterious effect of shock in internal mammary artery anastomoses. Ann Thorac Surg. 1989;47: 575-9.

4. Kaplan E, Meier P. Non-parametric estimation from incomplete observations. J Am Stat Assoc. 1958;53:457-81.

5. Zweig M, Campbell G. Receiver-operating characteristic (ROC) plots: a fundamental evaluation tool in clinical medicine. Clin Chem. 1993; 39:561-577.

6. Swets J. Measuring the accuracy of diagnostic systems. Science. 1988;240:1285-93.

7. Sergeant P, Blackstone E, Meyns B. Early and late outcome after
CABG in patients with evolving myocardial infarction. Eur J Cardiothorac Surg. 1997;11:848-56.

8. Hochman JS, Boland J, Sleeper LA, Porway M, Brinker J, Col J, et al. Current spectrum of cardiogenic shock and effect of early revascularisation on mortality. Circulation. 1995;91(3):873-81.

9. Hochman JS, Sleeper LA, Webb JG, Santorn TA, White HD, Talley $\mathrm{JD}$, et al. Early revascularisation in acute myocardial infarction complicated by cardiogenic shock. N Engl J Med. 1999;341(9):625-34.

10. Wollenek G, Honarwar N, Golej J, Marx M. Cold water submersion and cardiac arrest in treatment of severe hypothermia with cardiopulmonary bypass. Resuscitation. 2002;52(3):255-63.

11. Sergeant P, de Worm E, Meyns B. Single centre, single domain validation of the EuroSCORE on a consecutive sample of primary and repeat CABG. Eur J Cardiothorac Surg. 2001;20:1176-82.

\section{Discussion}

Dr Ludwig K. von Segesser (Lausanne, Switzerland). Given the difficult set of patients analyzed, a hospital mortality rate of $35 \%$ and an almost $50 \%$ survival after 10 years of follow-up is excellent. It comes as no surprise that early mortality is the main cause of loss of life and that patients requiring CPR do less well than patients with shock not requiring CPR.

Dr Sergeant, the observation period of this study is about 22 years, and therefore the mean number of patients operated on per year for shock is about 8 and for CPR is about 4 . It would be very interesting for the audience to know whether the distribution over time of the patients operated on is uniform. I am asking this because in our own experience, like in yours, the main cause of acute need of surgical intervention is an incident in the catheterization laboratory, for example, a crashed percutaneous transluminal coronary angioplasty. However, these events are unevenly distributed over time and much less frequent nowadays. If you get called in now for such patients, the myocardium has usually suffered already for a couple of hours, and all sorts of drugs, devices, and time have been wasted. Hence the patients we saw 20 years ago and those we see today are not exactly the same.

Furthermore, I would like to ask you to give us some insight in the delays observed between the initial event and the decision to go for surgical intervention, initiation of cardiopulmonary bypass, and delay until reperfusion. Is there a correlation between the time elapsed and outcome?

Dr Sergeant. Thank you, Professor von Segesser, for these questions. The first question is the prevalence or the incidence of these patients. Indeed, as you point out correctly, the prevalence is around 12 patients a year. You are correct that the patient's clinical condition might have changed over time. This becomes obvious on the basis of the importance of the biologic markers of " $\mathrm{pH}$ at entry of the operating theater" versus the cause leading to the operation.

Concerning the delay between the events: we have a system with 24-7 standby, basically on an around-the-clock basis. If our support is called in, we can be in 15 minutes on extracorporeal circulation around the clock. Therefore the delays are very short, but as you point out, the cardiologists and all our colleagues from different departments have spent a lot more time and energy in treating these patients. We have tried to build inferences from the chaotic clinical paths in all these different patients and bring this down in a more structured form.

Dr von Segesser. I had one last question to the expert in statistics you are. You write that a higher EuroSCORE is an independent predictor of mortality; however, EuroSCORE is the sum of semicontinuous and categoric variables having an arbitrary 
weight. Some are dependent of others, and some are not. How does your mathematic model handle this problem?

Dr Sergeant. Your comment is a very interesting one. In a total population of 259 patients, one cannot expect to obtain stable coefficient for rare variables. This is the reason we have chosen to use a composed variable, such as the EuroSCORE, to avoid this limitation. I have discussed this element in the Discussion section of the article.

Dr Charles Yankah (Berlin, Germany). Dr Sergeant, I would like you to comment on the troponin levels, cardiac indices, $\mathrm{SVO}_{2}$, and echocardiographic data on left ventricular wall thickness as determinant risk factors for early death in your patients receiving CPR before and after CABG. If you have those hemodynamic parameters, the heart failure scores indicating persistent heart failure within 12 to 24 hours after CABG, which are considered to be incremental risk factors and predictors for early death, which surgical-therapeutic concept would you advocate to improve the outcome of those patients who are unresponsive to medical therapy with intraortic counterpulsation?

Dr Sergeant. Of course these patients are very extensively monitored and studied. Troponin or creatine kinase levels are very dramatically influenced by the very early extended extracorporeal circulation. In more than half of these patients, we have taken electron microscopic biopsy specimens, and I can tell you that if your analysis is very correct and your electron microscopic analysis is very correct, one will identify necrosis of myocardial cells in nearly all of these patients. We have, of course, done ECG and echocardiographic studies in these patients.

Some governments have decided to reimburse only one echocardiograph over a whole year time frame, and these patients have, of course, an echocardiogram at the time of diagnosis of the disease during the operation and, in fact, every day in intensive care for the next days.

Dr Fabrizio Follis (Palermo, Italy). In your series there was a subset of patients who underwent redo procedures. In that case, what were the results, and is there is any different policy in treating redo patients?

Dr Sergeant. Late redo procedures have dramatic results. It turned out that in the mathematic models, after correction for variability, the effect of the redo situation was minimal and not any more within the rules of significance.

Dr Jeremy R. Morton (Portland, Me). You mentioned that you made fairly liberal use of the left ventricular assist device. I have 2 quick questions. First, has your overall experience with respect to survival in this class of patients improved over the years? Second, has your experience with the left ventricular assist device in these patients been sufficiently good for you to be enthusiastic about its use?

Dr Sergeant. That is a very difficult question. We have a very liberal use as well of rotary devices, as extracorporeal or intracorporeal devices. I tried to identify the effect of the date of the operation as an incremental risk factor in the survival, and it was not there. It could have been that the sample size was still too small. We would have been very proud in showing an improved survival now versus 10 years ago. We were not able to identify that.

Dr D. Craig Miller (Stanford, Calif). Paul, I noticed your oldest patient was 90 years old. It makes me wonder who you did not try to salvage?

Dr Sergeant. I must say I did not treat all these patients. I treated probably $70 \%$ of these. I do not always agree with everything that happens when I am not there, but I can tell you that this particular patient survived. The discriminatory power of a pivot value of 90 years of age is so reduced. And I think your question is very pertinent because I was upset when this patient had been treated, but the analysis shows that the discriminatory power of age is too low to predict. Therefore maybe we should indeed be treating that patient who is 90 years of age with a good $\mathrm{pH}$ at entry into the operating theater and maybe not a patient who is 40 years of age with a $\mathrm{pH}$ of 6.7 . 